\title{
Physical exercises in the treatment of idiopathic scoliosis at risk of brace treatment - SOSORT consensus paper 2005 Hans-Rudolf Weiss ${ }^{* \dagger 1}$, Stefano Negrini ${ }^{\dagger 2}$, Martha C Hawes ${ }^{\dagger 3}$, Manuel Rigo ${ }^{4}$, Tomasz Kotwicki ${ }^{5}$, Theodoros B Grivas ${ }^{6}$, Toru Maruyama ${ }^{7}$ and members of the SOSORT
}

\begin{abstract}
Address: ${ }^{1}$ Asklepios Katharina Schroth Spinal Deformities Rehabilitation Centre, Bad Sobernheim, Germany, ${ }^{2}$ ISICO (Italian Scientific Spine Institute), Milan, Italy, ${ }^{3}$ University of Arizona, Tucson AZ 85721, USA, ${ }^{4}$ Instituto Èlena Salvá, Barcelona, Spain, ${ }^{5}$ University of Medical Sciences, Poznan, Poland, ${ }^{6}$ Orthopaedic Department "Thriasion" General Hospital, Magula, Athens, Greece and ${ }^{7}$ Department of Orthopaedic Surgery, Teikyo University School of Medicine, 2-11-1 Kaga, Itabashi-ku, Tokyo 173-8605, Japan

Email: Hans-Rudolf Weiss* - hr.weiss@asklepios.com; Stefano Negrini - stefano.negrini@isico.it; Martha C Hawes - mhawes@u.arizona.edu; Manuel Rigo - lolo_rigo@ hotmail.com; Tomasz Kotwicki - tomaszkotwicki@poczta.onet.pl; Theodoros B Grivas - grivastb@panafonet.gr; Toru Maruyama -dr@maruyama.net; members of the SOSORT - hr.weiss@asklepios.com

* Corresponding author †Equal contributors
\end{abstract}

Published: II May 2006

Scoliosis 2006, I:6 doi:10.1186/1748-7/6I-1-6
Received: 06 December 2005

Accepted: II May 2006

This article is available from: http://www.scoliosisjournal.com/content///I/6

(c) 2006 Weiss et al; licensee BioMed Central Ltd.

This is an Open Access article distributed under the terms of the Creative Commons Attribution License (http://creativecommons.org/licenses/by/2.0), which permits unrestricted use, distribution, and reproduction in any medium, provided the original work is properly cited.

\begin{abstract}
Background: Based on a recognized need for research to examine the premise that nonsurgical approaches can be used effectively to treat signs and symptoms of scoliosis, a scientific society on scoliosis orthopaedic and rehabilitation treatment (SOSORT) was established in Barcelona in 2004. SOSORT has a primary goal of implementing multidisciplinary research to develop quantitative, objective data to address the role of conservative therapies in the treatment of scoliosis. This international working group of clinicians and scientists specializing in treatment of scoliosis met in Milan, Italy in January 2005.

Methods: As a baseline for developing a consensus for language and goals for proposed multicenter clinical studies, we developed questionnaires to examine current beliefs, before and after the meeting, regarding (I) the aims of physical exercises; (2) standards of treatment; and (3) the impact of such treatment performed by specialists in the field.

Results: The responses to the questionnaires show that, in principle, specialists in scoliosis physiotherapy do not disagree and that several features can be regarded, currently, as standard features in the rehabilitation of scoliosis patients. These features include autocorrection in 3D, training in ADL, stabilizing the corrected posture, and patient education.
\end{abstract}

\section{Background}

For treatment of all pediatric spinal deformities, the goal is to maintain function and prevent symptoms in the short- and long-term. In children with scoliosis, as summarized below, predictable signs and symptoms includ- ing pain and reduced pulmonary function begin early in life and worsen with age. Most curvatures still present at skeletal maturity also continue to worsen throughout life. For children with scoliosis, therefore, optimal treatment goals include reversing curvature magnitude and/or pre- 
venting curvature progression, pain, and pulmonary dysfunctionover a lifetime.

\section{Pain}

Most clinical outcome surveys have revealed that, by early adulthood, the majority of scoliosis patients suffer from pain [1-15]. Only one large, controlled survey has been carried out, to date [16]. In that study, 1178 young adults, interviewed 10 years after diagnosis in adolescence, reported a significantly higher incidence of pain than 1217 control subjects. Of the scoliosis patients reporting pain, 23\% (147/650) described it as 'horrible, excruciating, distressing' compared with $1 \%(6 / 416)$ of the control subjects who reported pain. Similar results were reported at $>44$ year followup [17]. Of a subset of 69 patients treated in adolescence (from an original population of 444), twice as many scoliosis patients (77\% vs $35 \%)$ suffered from pain compared with a population of adults of comparable age ( $>55$ years). Incidence of chronic pain was almost three fold higher in the scoliosis patients (61\%) compared with the controls without scoliosis (22\%). This is despite the fact that the 'control' popoulation was selected from hospital clinics, nursing homes, and senior citizens' centers where incidence of disability is exceptionally high $[18,19]$. How scoliosis causes pain is not clear, but the magnitude of pain in adult scoliosis patients recently has been found to be inversely proportional to curvature flexibility [20]. Related factors linked with pain include regional balance, instability and pathological mechanical loads on spinal elements [21].

\section{Pulmonary dysfunction}

Thoracic scoliosis in children results in characteristic signs of pulmonary dysfunction including reduced vital capacity (VC) and impaired exercise capacity (EC) [22-28]. Because the mechanism for impaired function is reduced mobility of the chest wall and such mobility deteriorates with age, pulmonary function deteriorates according to curvature magnitude even when the curvature itself does not progress [29-33]. In severe cases death occurs by respiratory failure [30-35]. The effects of reduced pulmonary function in patients with mild to moderate scoliosis are not known and have been dismissed as insignificant [e.g., [36,37]]. Recent studies, however, have shown that VC and EC characteristic of patients with mild to moderate scoliosis $(<85 \%$ predicted) are more reliable predictors of increased mortality than diabetes, high blood pressure, and heart disease [38-40]. Patient-described pulmonary symptoms, in general, are not a reliable indicator because patients usually are unaware of their limitations even when documented signs are severe and respiratory failure is imminent [29-33,41-43].

\section{Progression}

Once a flexible spinal curvature evolves into a spinal deformity, a 'vicious cycle' is initiated in which continuous asymmetric loading of the spinal elements fosters continued progression [44-46]. Only a few small surveys have examined the epidemiology of progression and insufficient information is available to reliably predict outcome for any given patient $[47,48]$. In general, the danger for dramatic progression is highest during periods of rapid growth, but most cases continue to progress throughout life $[1,15,48-50]$. Some individuals with similar curves exhibit marked progression after skeletal maturity while others are relatively stable [41]. The bases for such differences are unknown, though some have suggested that the likelihood of progression is greater the more rigid the curvature [51].

\section{Role of exercise in treatment of scoliosis}

Exercise based therapies, alone or in combination with orthopedic approaches, are a logical approach to improve and maintain flexibility and function in patients at risk for pain, pulmonary dysfunction, and progression. Data from the Schroth clinic in Bad Sobernheim, Germany reveal improved pulmonary function $[52,53]$ and reduced pain [54-56] in response to an intensive scoliosis in-patient rehabilitation (SIR) regime. Among the small number of studies which have examined it formally [56-63], progression was less in patient populations who were treated with exercise [reviewed in [64]]. When exercise was prescribed but was not carried out by the patients, progression was similar to untreated populations [60].

The role of exercise based therapies as discussed in the spine literature has been controversial, however, with often-repeated claims that research has shown that such approaches are ineffective in treating scoliosis [e.g. [6578]]. A systematic review of articles published in English throughout history produced no data in support of such claims [79]. As pointed out by Focarile et al., [80] in 1991, 'Experimental controlled studies of different therapies seem to be justified both on ethical and scientific grounds.'

SOSORT was established in 2004 to respond to a need for objective scientific information from independent sources. A meeting was held in Milan, Italy, to explore existing community perspectives regarding (1) the aims of physical exercises; (2) standards of treatment; and (3) the impact of such treatment performed by specialists in the field. The goal was to initiate a dialog for building a working consensus prior to initiation of multicenter research initiatives among members of SOSORT. 


\section{Methods}

\section{I. Premeeting-questionaire (before the consensus} meeting)

Questionnaires were prepared through consensus among the authors of the study. A first version was drafted by the second author, then critiqued and revised through electronic mail conference to produce a second edition. The second version was submitted to a pre-test by e-mail, to obtain the final form. The title of the questionnaire was "Therapeutic aims of physical exercise treatment in patients at risk of brace treatment."

The following clinical description was given:

Patient at the start of pubertal growth spurt. Curve at high risk of progression and high risk of prescription of a brace. You propose physical exercises to prevent progression.

The following questions were asked:

1. What are the therapeutic aims of the exercises you propose (i.e what do you want to improve?)

2. Which aims are more important (priority: 1 high -2 medium - 3 low)?

\section{Why do you choose these aims?}

\section{How do you obtain these aims?}

During the preparation of the study, the possibly relevant therapeutic aims of the exercises for scoliosis treatment were proposed by the second author and submitted to a preliminary consensus among the authors of this study: The final list was provided in the questionnaire, with space to answer to questions 2, 3 and 4 for each therapeutic aim chosen. The possibly relevant therapeutic aims of the exercises for scoliosis treatment identified by the authors included:

- Autocorrection 3D

- Autoelongation

- Coordination

- Equilibrium

- Ergonomy

- General motor capacity

- Muscular endurance

- Muscular strength
- Neuromotorial control of the spine

- Increase of Range of Motion

- Respiratory capacity

- Respiratory education

- Side-shift

- Stabilisation

Responders could add any relevant aim.

Questionnaires constituted the abstracts of the "SOSORT consensus meeting in Milan, January 2005." These were sent, together with the Preliminary Program, to all the attendees of the " 1 st International Meeting on Conservative Management of Spinal Deformities" held January 2004 in Barcelona. The program also was distributed to all others with interest in conservative treatment of adolescent idiopathic scoliosis that it was possible to retrieve according to the indexed literature. To gather the maximum possible range of opinions, it was required to fill in the questionnaire independently by the participation to the Consensus Meeting, and to reply by e-mail 1.5 months before the Meeting. 20 persons or institutions responded to the premeeting questionnaire.

\subsection{Postmeeting-questionnaire (after the consensus meeting)}

During the Milano consensus meeting the attendees were asked to fill in the questionnaires after formal discussion.

Thirty attendees took part and filled in the questionnaire to state their opinion about their aims when treating scoliosis patients by physiotherapy. The results can be seen on Table 2.

\section{Results}

\section{I. Premeeting-test (before the consensus meeting)}

The results are summarized in Table 1. Data were incomplete for some responders and statistical treatment was not attempted.

\section{I.I. Topics with general consensus}

The therapeutic aim rated highly important (Median 1) was 3D autocorrection having a high degree of consensus $(17 / 20)$.

\section{I.2. Topics with some consensus}

Topics with some consensus were respiratory capacity $(14 / 20)$ and respiratory education (12/20) (Median 1,5 $2,5=$ medium priority); equilibrium (Median $2=$ medium priority; 11/20), muscular strength (Median $2=$ 
Table I: Premeeting answers

\begin{tabular}{|c|c|c|c|c|}
\hline & Answers & Median & Min & $\operatorname{Max}$ \\
\hline Respiratory capacity & $70 \%$ & 2,5 & 0 & 3 \\
\hline Autocorrection 3D & $70 \%$ & I & 1 & 3 \\
\hline Respiratory education & $60 \%$ & 1,5 & 0 & 3 \\
\hline Equilibrium & $55 \%$ & 2 & 1 & 3 \\
\hline Muscular strength & $55 \%$ & 2 & 1 & 3 \\
\hline Autoelongation & $50 \%$ & 3 & 1 & 3 \\
\hline Increase of ROM & $50 \%$ & 3 & 1 & 3 \\
\hline Neuromotorial control & $50 \%$ & 1 & 1 & 3 \\
\hline Side-shift & $50 \%$ & 2 & 1 & 3 \\
\hline Stabilisation & $50 \%$ & I & 1 & 4 \\
\hline Muscular endurance & $45 \%$ & 2 & 1 & 3 \\
\hline Coordination & $40 \%$ & 2 & 1 & 3 \\
\hline Ergonomy & $35 \%$ & 2 & 2 & 3 \\
\hline General motor capacity & $25 \%$ & 2 & 1 & 2 \\
\hline Psychological aspects & $10 \%$ & l & 1 & l \\
\hline Scoliosis exercises in groups & $5 \%$ & I & 0 & 0 \\
\hline $\begin{array}{l}\text { Restoring of physiological spinal } \\
\text { curvatures (sagittal plane) }\end{array}$ & $5 \%$ & 1 & 1 & I \\
\hline $\begin{array}{l}\text { Correction of contractures and } \\
\text { muscles shortening }\end{array}$ & $5 \%$ & 1 & 1 & 1 \\
\hline Proprioception and tactile & $5 \%$ & 3 & 3 & 3 \\
\hline Neurodynamics & $5 \%$ & 3 & 3 & 3 \\
\hline $\begin{array}{l}\text { Theoretical information for the patient } \\
\text { and family }\end{array}$ & $5 \%$ & 3 & 3 & 3 \\
\hline Activities of daily living & $5 \%$ & 1 & 1 & I \\
\hline Self perception & $5 \%$ & 3 & 3 & 3 \\
\hline In - brace exercises & $5 \%$ & 3 & 3 & 3 \\
\hline
\end{tabular}

medium priority; 11/20), neuromotorical control (Median $1=$ high priority; 10/20) and stabilisation (Median 1 = high priority; 10/20).

The other aims given were not rated with a high priority. Nevertheless some consensus was found, with at least 5/ 20, for instance, considering an improvement of general motor capacity necessary.

\section{I.3. Topics with no consensus}

Aims added by certain authors included the following:

\section{Exercise in groups}

Exercises in groups is performed during Scoliosis Inpatient Rehabilitation (SIR) in Germany and Barcelone, but also in Switzerland and Israel. The positive psychological impact on scoliosis patients who are rather alone with their deformity helps to cope with the disorder [81-83].

Restoration of sagittal profile

This is an integral component '3D Autocorrection' [82].

\section{Psychology}

Psychological aspects play a key role in physiotherapy. The question is which methodology to be taken and
Table 2: Postmeeting answers. Preferences relate to number of people who chose the single answer, while percentages relate only to people who had a preference to each single aim

\begin{tabular}{|c|c|c|c|c|}
\hline \multirow[t]{2}{*}{ Answers: 30} & \multirow{2}{*}{$\begin{array}{c}\text { Preferences } \\
\%\end{array}$} & \multicolumn{3}{|c|}{ Priorities } \\
\hline & & $\mathbf{I}$ & 2 & 3 \\
\hline Autocorrection 3D & $97 \%$ & $90 \%$ & $0 \%$ & $7 \%$ \\
\hline $\begin{array}{l}\text { Theoretical information for the } \\
\text { patient and family }\end{array}$ & $87 \%$ & $53 \%$ & $27 \%$ & $7 \%$ \\
\hline Stabilisation & $87 \%$ & $50 \%$ & $23 \%$ & $13 \%$ \\
\hline Self perception & $87 \%$ & $43 \%$ & $33 \%$ & $10 \%$ \\
\hline Activities of daily living & $83 \%$ & $53 \%$ & $20 \%$ & $10 \%$ \\
\hline Muscular endurance & $83 \%$ & $30 \%$ & $33 \%$ & $20 \%$ \\
\hline Psychological aspects & $77 \%$ & $43 \%$ & $20 \%$ & $13 \%$ \\
\hline Respiratory education & $77 \%$ & $27 \%$ & $27 \%$ & $23 \%$ \\
\hline Neuromotorial control of the spine & $70 \%$ & $33 \%$ & $30 \%$ & $7 \%$ \\
\hline Proprioception and tactile & $70 \%$ & $27 \%$ & $33 \%$ & $10 \%$ \\
\hline Equilibrium & $70 \%$ & $20 \%$ & $37 \%$ & $13 \%$ \\
\hline $\begin{array}{l}\text { Restoring of physiological spinal } \\
\text { curvatures (sagittal plane) }\end{array}$ & $67 \%$ & $57 \%$ & $7 \%$ & $3 \%$ \\
\hline Respiratory capacity & $67 \%$ & $17 \%$ & $23 \%$ & $27 \%$ \\
\hline Ergonomy & $67 \%$ & $10 \%$ & $30 \%$ & $27 \%$ \\
\hline $\begin{array}{l}\text { Correction of contractures and } \\
\text { muscles shortening }\end{array}$ & $63 \%$ & $23 \%$ & $30 \%$ & $10 \%$ \\
\hline Scoliosis exercises in groups & $63 \%$ & $10 \%$ & $33 \%$ & $20 \%$ \\
\hline Renge of Motion & $63 \%$ & $7 \%$ & $30 \%$ & $27 \%$ \\
\hline Coordination & $60 \%$ & $13 \%$ & $37 \%$ & $10 \%$ \\
\hline General motor capacity & $60 \%$ & $3 \%$ & $37 \%$ & $20 \%$ \\
\hline Muscular strength & $57 \%$ & $10 \%$ & $27 \%$ & $20 \%$ \\
\hline Side-shift & $53 \%$ & $23 \%$ & $23 \%$ & $7 \%$ \\
\hline Autoelongation & $53 \%$ & $13 \%$ & $27 \%$ & $13 \%$ \\
\hline In - brace exercises & $50 \%$ & $10 \%$ & $23 \%$ & $17 \%$ \\
\hline Neurodynamics & $50 \%$ & $7 \%$ & $33 \%$ & $10 \%$ \\
\hline
\end{tabular}

whether PT's are the right professionals trained also in psychological direction. Anyway we have a good psychological impact from group sessions and therefore the question is whether to make specific group training a standard procedure in physical therapy of scoliosis [83].

Correction of contractures

When there are any, surely is of importance when contractures inhibit 3D correction, however not with high priority.

\section{Proprioception}

The use of proprioception, tactile stimulation to improve neurodynamics and self perception is important and is an integral part of many treatment programs to facilitate $3 \mathrm{D}$ correction $[82,83]$.

\section{Patient and family education}

Theoretical information for the patient and family is very important and should be given by physiotherapists as well as by the guiding physician. Generally, training of PT's in theory of scoliosis rehabilitation also is necessary [83]. 
Activities of daily living (ADL)

ADS is performed as a specialized module of treatment during SIR $[81,83,86]$. But this aim to address ADL should also follow a standardized methodology, perhaps as an addition to the aim to improve ergonomy.

\section{Exercise and brace treatment}

In brace-treated patients, exercises are not performed regularily in the centre of the senior author but their proposed importance, and the evidence to support this, should be discussed.

\section{Awareness of the deformation}

This important issue, also classified at 'self perception' is integrated into the Lyonaise Method [84,85] and the Schroth programme $[82,83,86]$ as a component of diagnosis and education, as well as a baseline for 'before and after' evaluation.

\subsection{Postmeeting-questionaire (after the consensus meeting)}

The results of the postmeeting-test changed slightly compared to the premeeting values (Table 2). The choice for highest priority for treatment aims were:

Autocorrection in 3D (97\%),

Restoration of the sagittal alignment (67\%),

ADL-training (83\%),

Theoretical information to the patient (87\%),

Stabilisation (87\%).

\section{Discussion}

In 1941, a committee of the American Orthopaedic Association undertook a study of methods and results of treatment of idiopathic scoliosis, by interviewing clinicians at sixteen clinics in the United States [87]. Case histories of 425 patients, followed for $>1$ year after treatment, were evaluated. The goal of the study was to 'establish the present status of this condition, and to clarify, in so far as possible, what can be expected from the present methods of treatment.'

At that time, most clinics prescribed a regime of specialized exercises and/or surgery [87]. Short term results obtained with surgery and with exercise were similar, with little or no improvement obtained for most patients. Among 214 patients treated with spinal fusion, significant loss of correction occurred in $92 \%$ of patients, and in $30 \%$ of cases the curvature was the same or worse after surgery than before. Long term complications were not available but at short-term followup, the results in $69 \%$ of treated patients were rated as 'fair' or 'poor.' Among 185 patients treated with exercise at the 16 clinics surveyed, 69\% either remained unchanged or increased by 5-15 degrees, $27 \%$ increased by $\geq 20$ degrees, and one curve improved by $>10$ degrees. Questionnaires revealed that 'most men agree that postural improvement can be expected from a regime of exercises, but the curve itself cannot be decreased by this means.'

In the ensuing decades since this study was published, the routine use of exercise for patients in the United States was largely eliminated (e.g., 65-78). Meanwhile, an ongoing global effort to develop effective surgical methods is reflected in $>10,000$ peer reviewed articles published, in English, since 1950 and listed in Medline and other searches for scholarly articles. Unfortunately, the lack of success with exercise reported in 1941, unlike the failure of surgery, has not led to a corresponding effort to define improved methods for using physical therapy to treat patients with scoliosis: A parallel search of Medline reveals that fewer than 100 articles exploring the use of exercise-based approaches in the treatment of scoliosis in patients, of any age, have been published.

The routine use of exercise has remained central to therapeutic approaches in many countries [88]. To date, however, the body of literature available to patients and clinicians is of limited use [64]. The relatively limited literature in part reflects clinical traditions which have not placed a high priority on publication. Perhaps more important, a diversity of approaches, standards, and languages limits how accessible and interpretable the available information is to colleagues with common interests [64]: Among several hundred reports of clinical outcome published in recent decades (>600), no fewer than ten different languages were used. The establishment of a scientific society dedicated to research into scoliosis rehabilitation, and a venue for rigorous peer review of results from specialists, are critical first steps in defining the role of physical therapy in treatment of scoliosis.

\section{Conclusion}

A foundational meeting of SOSORT, a new international scientific society dedicated to research on scoliosis rehabilitation, met in Milan, Italy in January 2005. Questionnaires, given before and after the meeting, were used to explore current beliefs, approaches, and goals in clinical practice. The responses to the questionnaires show that, in principle, specialists in scoliosis physiotherapy do not disagree and that several features can be regarded, currently, as standard features in the rehabilitation of scoliosis patients. These features include autocorrection in 3D, training in ADL, stabilizing the corrected posture, and patient education. However, due to a lack of common standards and common terminology the meaning of 
some questions were understood quite differently. A priority for SOSORT will be to foster a common language and therapeutic standards among the international community specializing in conservative scoliosis management. With the establishment of a clinical and conceptual framework for communication and planning, multicenter studies can be designed to measure the short and longterm efficacy of these approaches in maintaining health and function in children diagnosed with scoliosis.

\section{Author contributions}

MR, TK, TBG, and TM contributed by reviewing, text editing and adding certain textfiles and references.

\section{Competing interests}

The author(s) declare that they have no competing interests.

\section{References}

I. Ascani E, Bartolozzi P, Logroscino CA, Marchetti PG, Ponte A, Savini $R$, Travaglini F, Binazzi R, Di Silvestre $M$ : Natural history of untreated IS after skeletal maturity. Spine 1986, I I:784-789.

2. Collis DK, Ponseti IV: Long-term follow-up of patients with IS scoliosis not treated surgically. J Bone Jt Surg 1969, 5IA:425-445

3. Fowles JV, Drummond DS, L'Ecuyer S, Roy L, Kassab MT: Untreated scoliosis in the adult. Clinical Orthop Related Res 1978, I34:212-22.

4. Nachemson A: A long term follow-up study of nontreated scoliosis. Acta Orthop Scan 1968, 39:466-476.

5. Balague F, Dutoit G, Waldburger M: Low back pain in schoolchildren. An epidemiological study. Scandinavian / Rehab Med 1988 20: I75- 179 .

6. Edgar MA: Back pain assessment from a long term follow-up of operated and unoperated patients with AIS. Spine 1979 4:519-521.

7. Fairbank JC, Pynsent PB, Van Poortvliet JA, Phillips H: Influence of anthropometric factors and joint laxity in the incidence of adolescent back pain. Spine 1984, 9:46।-464

8. Kostuik JP, Bentivoglio J: The incidence of low back pain in adult scoliosis. Spine 1981, 6:268-273.

9. Jackson RP, Simmons EH, Stripinis D: Incidence and severity of back pain in adult idiopathic scoliosis. Spine 1983, 8:749-756.

10. Mayo NE, Goldberg MS, Poitras B, Scott S, Hanley J: The Ste-Justine AIS cohort study. Part III: Back pain. Spine I994, I4: I573-I58I.

II. Nastasi AJ, Levine DB, Veliskakis KP: Pain patterns in AIS. J Bone Jt Surg 1972, 54-A: I575.

12. Nilsonne U, Lundgren K: Long term prognosis in IS. Acta orthop Scandinav 1968, 39:456-465.

13. Ramirez N, Johnston CE, Browne RH: The prevalence of back pain in children who have IS. I Bone Jt Surg I997, 79-A:364-368.

14. Vitale MG, Levy DE, Johnson MG, Gelijns AC, Moskowitz AJ, Roye $B P$, Verdisco L, Roye DP: Assessment of quality of life in adolescent patients with orthopedic problems: Are adult measures appropriate? J Ped Orthop 2001, 21:622-628.

15. Weinstein SL, Zavala DC, Ponseti IV: Idiopathic scoliosis: Iong term follow-up and prognosis in untreated patients. J Bone $J t$ Surg 198I, 63-A:702-712.

16. Goldberg MS, Mayo NE, Poitras B, Scott S, Hanley J: The Ste-Justine Adolescent Idiopathic Scoliosis Cohort Study. Part II: Perception of health, self and body image, and participation in physical activities. Spine 1994, I4:1562-I572.

17. Weinstein SL, Dolan LA, Spratt KF, Peterson KK, Spoonamore MI Ponseti IV: Health and function of patients with untreated IS: a 50-year natural history study. JAMA 2003, 289:559-567.

18. Bishop $\mathrm{C}$ : Where are the missing elders? The decline in nursing home use, 1985-1995. Health Affairs 1999, I 8:146-I55.

19. Weinstein SL: Health and function with untreated scoliosis reply. JAMA 2003, 289:2644.
20. Deviren V, Berven S, Kleinstueck F, Antinnes J, Smith JA, Hu SS: Predictors of flexibility and pain patterns in thoracolumbar and lumbar IS. Spine 2002, 27:2346-2349.

2I. Schwab FJ, Smith VA, Biserni M, Gamez L, Farcy JP, Pagala M: Adult scoliosis:quantitative radiographic and clinical analysis. Spine 2002, 27:387-392.

22. Chong KC, Letts RM, Cumming GR: Influence of spinal curvature on exercise capacity. J Ped Orthop I98I, I:25 I-254.

23. DiRocco P, Breed AL, Carlin JI, Reddan WG: Physical work capacity in adolescents with mild IS. Arch Phys Med Rehab 1983, 64:476-479

24. DiRocco P, Vaccaro P: Cardiopulmonary functioning in adolescent patients with mild IS. Arch Phys Med Rehab 1988 , 69:198-199.

25. Smyth RJ, Chapman KR, Wright TA, Crawford JS, Rebuck AS: Pulmonary function in adolescents with mild IS. Thorax 1984, 39:901-904.

26. Smyth RJ, Chapman KR, Wright TA, Crawford MD, Rebuck AS: Ventilatory patterns during hypoxia, hypercapnia, and exercise in adolescents with mild scoliosis. Pediatrics 1986, 77:692-696.

27. Szeinberg A, Canny G], Rashed N, Veneruso G, Levison H: Forced VC and maximal respiratory pressures in patients with mild and moderate scoliosis. Ped Pulmon 1988, 4:8-I2.

28. Weber B, Smith JP, Briscoe WA, Friedman SA, King TKC: Pulmonary function in asymptomatic adolescents with IS. Am Rev Resp Dis 1975, I | | :389-397.

29. Fraser RS, Muller NL, Colman N, Pare PD: Fraser and Pare's Diagnosis of Diseases of the Chest Fourth edition. Philadelphia: WB Saunders; 1999.

30. Murray JF, Nadel JA: Textbook of Respiratory Medicine 3rd edition. Philadelphia: WB Saunders; 2000.

31. Branthwaite MA: Cardiorespiratory conequences of unfused IS. $\mathrm{Br} J$ Dis Chest 1986, 80:360-369.

32. Davies G, Reid L: Effect of scoliosis on growth of alveoli and pulmonary arteries and on the right ventricle. Archives of Disease in Childhood 1971, 46:623-632.

33. Hitosugi $M$, Shigeta $A$, Takatsu $A$ : An autopsy case of sudden death in a patient with IS. Medicine Science and the Law 2000, 40: $175-178$.

34. Pehrsson K, Larsson S, Oden A, Nachemson A: Long term followup of patients with untreated scoliosis. A study of mortality, causes of death and symptoms. Spine 1992, I 7:1091-1096.

35. Schneerson JM, Sutton GC, Zorab PA: Causes of death, right ventricular hypertrophy, and congenital heart disease in scoliosis. Clin Orth Rel Research 1978, I 35:52-57.

36. Dickson RA: Spinal deformity - AIS. Nonoperative treatment. Spine 1999, 24:2601-2606.

37. Dickson RA, Weinstein SL: Bracing (and screening) - yes or no? J Bone Jt Surg 1999, 81-B:193-198.

38. Mannino DM, Buist AS, Petty TL, Enright PL, Redd SC: Lung function and mortality in the U.S.: data from the First National Health and Nutrition Examination Survey followup study. Thorax 2003, 58:388-393.

39. Karlson BW, Sjolin M, Lindqvist J, Caidahl K, Herlitz J: Ten-year mortality rate in relation to observations of a bicycle exercise test in patients with a suspected or confirmed ischemic event but no or only minor myocardial damage. American Heart Journal 2001, 141:977-984.

40. Myers J, Prakash M, Froelicher V, Do D, Partington S, Atwood JE: Exercise capacity and mortality among men referred for exercise testing. New England Journal of Medicine 2002 346:793-80I.

4I. Collis DK, Ponseti IV: Long-term follow-up of patients with IS scoliosis not treated surgically. I Bone It Surg 1969, 5IA:425-445.

42. Drummond DS, Rogala E, Gurr J: Spinal deformity: Natural history and the role of screening. Orthop Clinics of NA 1979 , 10:751-759.

43. Weiss HR, Bickert W: Improvement of the parameters of right-heart stress evidenced by electrocardiographic examinations by the in-patient rehabilitation program according to Schroth in adult patients with scoliosis. Orthop Prax 1996, 32:450-453.

44. Roaf R: Scoliosis Baltimore: Williams and Wilkins; 1966.

45. Stokes IAF, Hueter-Volkmann : Effect. State of the Art Reviews. Spine 2000, I 4:349-357. 
46. Stokes IAF, Gardner-Morse M: The role of muscles and effects of load on growth. Research into Spinal Deformity 2002, 4:3।4-3I7.

47. Lonstein JE, Carlson JM: The prediction of curve progression in untreated idiopathic scoliosis during growth. J Bone Jt Surg [Am.] 1994, 66: I06I.

48. Weinstein SL: Natural history. Spine 1999, 24:2592-2600.

49. Bjerkreim R, Hassan I: Progression in untreated IS after the end of growth. Acta Orthop Scand 1982, 53:897-900.

50. Weinstein SL, Ponseti IV: Curve progression in IS. Bone Jt Surg 1983, 65-A:447-455.

5I. Lonstein JE, Winter RB: AIS: Nonoperative treatment. Orth Clinics NA 1988, 19:239-245.

52. Weiss HR: The effect of an exercise programme on VC and rib mobility in patients with IS. Spine 1991, 16:88-93.

53. Weiss HR, Bickert W: Improvement of the parameters of right-heart stress evidenced by electrocardiographic examinations by the in-patient rehabilitation program according to Schroth in adult patients with scoliosis. Orthop Prax 1996, 32:450-453.

54. Weiss HR: Scoliosis related pain in adults - treatment influences. Eur J Phys Med and Rehab 1993, 3:91-94.

55. Weiss HR, Verres C, Lohschmidt K, El Obeidi N: Pain and scoliosis - is there any relationship? Orthop Prax 1998, 34:602-606.

56. Ferraro C, Masiero S, Venturin A: Effect of exercise therapy on mild idiopathic scoliosis. Preliminary result. Europa Medico Physica 1998, 34:25-31.

57. Rigo M, Quera-Salva G, Puigdevall N: Effect of the exclusive employment of physiotherapy in patients with idiopathic scoliosis. In Proceedings Book III of the I I th International Congress of the World Confederation for Physical Therapy:July28th - August 2nd. 1991 London, Chartered Society of Physiotherapists; 1991:1319-1321.

58. Weiss HR: Influence of an in-patient exercise program on scoliotic curve. Italian Journal of Orthopedics and Traumatology 1992, 18:395-406.

59. Weiss HR, Lohschmidt K, El Obeidi N, Verres C: Preliminary results and worst-case analysis of in-patient scoliosis rehabilitation. Ped Rehab 1997, I:35-40.

60. Stone B, Beekman C, Hall V, Guess V, Brooks HL: The effect of an exercise program on change in curve in adolescents with minimal idiopathic scoliosis. A preliminary study. Physical Therapy 1979, 59:759-763.

61. Den Boer WA, Anderson PG, Limbeek: Treatment of idiopathic scoliosis with side-sthift therapy: an initial comparison with a brace treatment historical cohort. Eur Spine J 1999, 8:406-410.

62. Weiss HR, Lohschmidt K, El Obeidi N, Verres C: Preliminary results and worst-case analysis of inpatient scoliosis rehabilitation. Ped Rehab 1997, 1:35-40.

63. Weiss HR, Weiss G, Petermann F: Incidence of curvature progression in idiopathic scoliosis patients treated with scoliosis in-patient rehabilitation (SIR): an age- and sex-matched controlled study. Ped Rehab 2003, 6:23-30.

64. Negrini S, Antonini G, Carabalona R, Minozzi S: Physical exercises as a treatment for adolescent idiopathic scoliosis. A systematic review. Ped Rehab 2003, 6:227-235.

65. Bleck E: AIS. Developmental Med Child Neurol 1991, 33:167-176

66. Boachie-Adjei O, Onner B: Spinal Deformity (Common Orthopedic Problems I). Ped Clinics NA 1996, 43:883-897.

67. Bunnell WP: Nonoperative treatment of spinal Deformity ofspinal Deformity: the case for observation. Instructional Course Lectures 1985, 34:106-109.

68. Farady JA: Current principles in the nonoperative management of structural AIS. Physical Therapy 1983, 63:5 I2-523.

69. Haasbeek JF: AIS; recognizing patients who need treatment. Postgraduate Medicine 1997, 101:207-216.

70. Kaelin DL, Oh TH, Lim PAC: Rehabilitation of orthopedic and rheumatologic disorders. 4. Musculoskeletal disorders. Arch Phys Med Rehab 2000, 81:73-77.

7I. Killian JT, Mayberry S, Wilkinson L: Current concepts in AIS. Pediatric Annals 1999, 28:755-76I.

72. Leatherman K, Dickson R: The Management of Spinal Deformities London, Boston, Singapore, Sydney, Toronto, Wellington: Wright Press; 1988.

73. Lonstein JE: AIS. Lancet 1994, 344:|407-|4|2

74. Lonstein JE: Patient Evaluation. In Moe's Textbook of Scoliosis and Other Spinal Deformities 3rd edition. Edited by: Lonstein JE, Bradford D, Winter R, Oglivie J. Philadelphia: WB Saunders; 1995:45-86.
75. Reamy BV, Slakey JB: AIS: review and current concepts. American Family Physician 200 I, 64: I I I-I I6.

76. Rinsky LA: Advances in management of IS. Hospital Practice 1992:49-55.

77. Rinsky LA, Gamble JG: AIS. Western J Med 1988, |48:|82-191.

78. Roach JW: Disorders of the pediatric and adolescent spine. Orthop Clinics NA 1999, 30:353-65.

79. Hawes M: The use of exercise in the treatment of scoliosis: an evidence-based critial review of the literature. Ped Rehab 2003, 6: $17 \mid-18$.

80. Focarile FA, Bonaldi A, Giarolo M, et al.: Effectiveness of nonsurgical treatment for IS; overview of available evidence. Spine 1991, 16:395-401.

8I. Freidel K, Petermann F, Reichel D, Steiner A, Warschburger P, Weiss HR: Quality of life in women with idiopathic scoliosis. Spine 2002, I5:87-9|.

82. Weiss HR, Rigo M: Fisiotherapia para la Escoliosis (Basada en el diagnóstico) Paidotribo, Barcelone; 2004.

83. Weiss HR: La rehabilitatión de la escoliosis Paidotribo, Barcelone; 2003.

84. Negrini A: Die Idiopathische Skoliose des Adoleszenten Wissenschaftliche Erkenntnisse und Behandlungsverfahren [abstract of a paper read at the 17th. GEKTS meeting Louvain, Belgium 1989]. In Wirbelsäulendeformitäten Volume I. Edited by: Weiss HR. Heidelberg: Springer; 1991:88

85. Truchi P: Die muskuläre „Wachsamkeit” in den Übungen für Skoliosepatienten [abstract of a paper read at the 17th. GEKTS meeting Louvain, Belgium 1989]. In Wirbelsäulendeformitäten Volume I. Edited by: Weiss HR. Heidelberg: Springer; | $991: 89$

86. Lehnert-Schroth Ch: Dreidimensionale Skoliosebehandlung 6th edition. Stuttgart: Urban \& Fischer; 2000.

87. Shands AR, Barr JS, Colonna PC, Noall L: End-result study of the treatment of idiopathic scoliosis. Report of the Research Committee of the American Orthopedic Association. J Bone It Surg 194I, 23-A:963-977.

88. Moen KY, Nachemson AL: Treatment of scoliosis: an historical perspective. Spine 1999, 24:2570-2575.
Publish with BioMed Central and every scientist can read your work free of charge

"BioMed Central will be the most significant development for disseminating the results of biomedical research in our lifetime. "

Sir Paul Nurse, Cancer Research UK

Your research papers will be:

- available free of charge to the entire biomedical community

- peer reviewed and published immediately upon acceptance

- cited in PubMed and archived on PubMed Central

- yours - you keep the copyright
BioMedcentral 